\title{
‘Haal de vroedvrouw!' Over medische vaktermen in het audiovisueel vertalen. Een vergelijkende analyse naar aanleiding van de Nederlandse en Poolse vertaling van de Britse tv-serie Call the Midwife ${ }^{1}$
}

\section{'Call the midwife!' On medical terms in audiovisual translation. A contrastive analysis based on the translation of the British TV series Call the Midwife into Dutch and Polish}

Michał Gąska

\begin{abstract}
TV series which depict the sphere of a certain occupational field enjoy great popularity among their viewers who are waiting impatiently for every new episode. Since these series reflect a work sphere, an occupationally specific jargon is commonly used by their protagonists. In audiovisual texts specialist terms, which characterize such jargon, often pose a challenge for translators in the translation process. Not only the language proficiency of the translator is put to the test but also his/her specialized knowledge and competences.

The present article discusses the rendering of medical terms in audiovisual translation based on the British medical TV series Call the midwife. For this purpose, its subtitles into Dutch and Polish are scrutinized. The article aims at presenting translation techniques used to render the medical terms so that they are comprehensible for a layman viewer. The analysis is carried out considering the role of the visual depiction of the scenes and the influence of constraints, which are imposed on the translator in dealing with subtitles.
\end{abstract}

\section{Keywords}

audiovisual translation; subtitles; TV series; medical terms; translation technique; restriction

1 De onderhavige bijdrage is een verkorte en bewerkte versie van een masterscriptie met de titel „Medische vaktermen in het audiovisuele vertalen naar aanleiding van de Nederlandse en Poolse versies van de Britse tv-serie Call the Midwife". De scriptie werd onder leiding van dr. Jacek Karpiński geschreven en op 13.06.2017 succesvol verdedigd. 


\section{Inleiding}

Tv-series die de werksfeer van een bepaalde beroepsgroep afbeelden, genieten een steeds grotere populariteit. De kijkers volgen nieuwsgierig de handelingen van de protagonisten, die als juristen in de rechtszaal, chirurgen in operatiekamer, artsen in spoedopname of brandweerlieden in actie optreden. Omdat deze tv-series de werksfeer van bepaalde beroepsgroepen afschilderen, wordt er door de protagonisten vaak een beroepsspecifiek vakjargon gebruikt. Hierdoor heeft de toeschouwer de indruk alsof hij of zij met echte artsen of juristen te maken heeft. Bijgevolg komen er in dergelijke tv-series veel vaktermen voor die een uitdaging vormen voor de vertalers.

In de onderhavige bijdrage wordt de problematiek van het vertalen van medische vaktermen in interlinguale ondertiteling uiteengezet. De analyse wordt uitgevoerd op basis van het eerste seizoen van de Britse tv-serie Call the midwife. Deze tv-serie is een filmadaptatie van de gelijknamige roman van Jeniffer Worth. Zowel de roman als de tv-serie tonen het leven van een jonge vroedvrouw die met haar werk in de arme wijk East End in Londen in late jaren 50 van de vorige eeuw begint.

Hoewel in verschillende taalgebieden soms verschillende voorkeuren bestaan (in het Nederlandstalige gebied gaat het meestal om interlinguale ondertiteling, in Polen om voice-over ${ }^{2}$ ), wordt in dit artikel uitsluitend de interlinguale ondertiteling van de tv-serie geanalyseerd. De reden hiervoor is dat deze verschillende soorten audiovisueel vertalen zich technisch van elkaar onderscheiden, zodat er andere criteria bij de analyse ervan gehanteerd zouden moeten worden.

De analyse wordt uitgevoerd op basis van Nederlandse en Poolse versies van het bovenvermelde tv-programma. Daarbij gaat de aandacht naar de in de tv-serie voorkomende medische vaktermen. Ook wordt gekeken naar de invloed van het beeld op het vertaalproces en de gebruikte vertaaltechnieken. Het doel van het artikel is om aanschouwelijk te maken, met welke vertaaltechnieken de geanalyseerde vaktermen vertaald zijn en welke invloed de beperkingen hadden die de interlinguale ondertiteling aan de vertaler oplegt.

\section{Het audiovisueel vertalen}

Het audiovisueel vertalen is een relatief recente tak van vertaalwetenschap, die een steeds grotere populariteit geniet bij vertaalwetenschappers. Het is een bijzonder soort van vertalen dat twee aspecten bijeenhoudt:

Einerseits wird die audiovisuelle Übersetzung mit den Problemen, die auch bei anderen Textsorten auftreten und die durch die allgemeine Übersetzungstheorie definiert wurden, konfron-

2 Dit geldt voor de Poolse omroep. Op de Poolse televisie worden anderstalige films en programma's meestal met voice-over uitgezonden (in de Poolse bioscopen daarentegen of gedubd of ondertiteld) (Tomaszkiewicz 2008: 116; Plewa 2014). Als een televisieprogramma op DVD verschijnt, mag de toeschouwer dan kiezen of hij naar de tv-serie met voice-over of met ondertiteling wil kijken. 
tiert, andererseits kommen die Spezifik dieser Übersetzungsart und die Beschränkungen die die einzelnen Übersetzungsmethoden dem Translator auferlegen, hinzu (Korycińska-Wegner 2011: 62).

Tryuk (2008: 26) wijst erop dat onderzoekers het niet eens zijn of in het geval van audiovisueel vertalen alleen het verbale vlak van het bronmateriaal vertaald wordt, dan wel of ook de samenhang van het visuele vlak (het beeld) en het auditieve vlak (verbaal en non-verbaal) van het materiaal van belang is. Op basis van de indeling van het vertalen die door Roman Jakobson werd ingevoerd ${ }^{3}$, beweert Tomaszkiewicz (2008: 67) dat het audiovisueel vertalen als intersemiotisch beschouwd moet worden. Haar mening motiveert zij door op te merken dat het kenmerkend is voor dit soort vertalen dat de vertaler zijn vertaalstrategieën aan de technische vereisten van media zoals televisie, films of internet moet aanpassen. Bijgevolg moet hij niet alleen het talige aspect, maar ook andere elementen die van belang zijn in aanmerking nemen, zoals het meest belangrijke: het beeld (Tomaszkiewicz 2008: 66). Hoewel het beeld een grote rol speelt in het audio - visueel vertalen, berust de taak van de vertaler alleen op de interlinguale transfer, omdat hij in het visuele vlak niet kan ingrijpen.

\subsection{Interlinguale ondertiteling ${ }^{4}$}

In het geval van de ondertiteling wordt een onderscheid gemaakt tussen interlinguale ondertiteling, intralinguale ondertiteling en ondertiteling voor slechthorenden. ${ }^{5}$ In het algemeen gaat het om een verkorte vertaling van filmdialogen die als tekst op het beeld te zien zijn, terwijl de film met het originele dialoogspoor loopt (Jüngst 2010: 25).

Untertitel als Übersetzungsmittel können definiert werden als Übertragung in eine andere Sprache von verbalen Nachrichten im filmischen Medium in Form eines ein- oder mehrzeiligen Schrifttextes, die auf der Leinwand erscheinen und zwar gleichzeitig mit der originalen gesprochenen Nachricht (Gottlieb 2002: 187v.).

Uit de definitie van Gottlieb blijkt dat in het geval van de interlinguale ondertiteling de film onveranderd blijft. In tegenstelling tot nasynchronisatie wordt er niet ingegrepen in een belangrijk element van het spel van een acteur: zijn stem (Belczyk 2007: 6). Omdat het dialoogspoor in zijn originele vorm blijft, hebben de toeschouwers de gelegenheid naar een film in een vreemde taal te kijken. Dit voordeel wordt door vele wetenschappers

3 Het gaat hier om het intralinguale, interlinguale en intersemiotische vertalen (ook transmutatie genoemd).

4 De interlinguale ondertiteling vormt een complex onderwerp. Vanwege omvangbeperkingen worden hier slechts de meest belangrijke aspecten van dit soort vertalen besproken. Uitvoerig over dit soort vertalen schrijven bv. Díaz Cintas en Remael (2014).

5 Omdat in deze bijdrage uitsluitend de interlinguale ondertiteling wordt geanalyseerd, wordt er niet dieper ingegaan op de overige soorten ondertiteling. 
onderstreept die zich bezighouden met audiovisueel vertalen (vgl. Jüngst 2010: 27; Belczyk 2007: 6). Het feit dat interlinguale ondertiteling goedkoper is dan nasynchronisatie of voice-over mag ook niet buiten beschouwing gelaten worden (vgl. Díaz Cintas 2010: 344).

\subsection{De rol van het beeld in het audiovisueel vertalen}

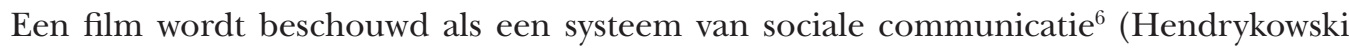
1994: 99), d.w.z. een overlevering van informatie door communicatie tussen de afzender (meestal gemeenschappelijk) en de ontvanger van media, omdat de film gebruik maakt van kanalen zoals bioscoop of televisie (Pisarek 2006: 58). In een dergelijk systeem wordt een film als een geëxternaliseerd bericht beschouwd. Dit bericht is een mentaal onderwerp dat zich in het hoofd van de afzender bevindt, d.w.z. van de schepper van de film. Hij uit zijn bericht met behulp van verschillende middelen en dit proces wordt als externalisatie van het bericht van de afzender beschouwd. De ontvanger heeft geen directe toegang tot het bericht van de afzender. Hij is alleen in staat dit bericht te reconstrueren op basis van de uitingen die de afzender hem presenteert. Plewa (2015: 76) onderscheidt vier soorten uitingen:

- visuele uitingen;

- auditieve uitingen;

- olfactorische uitingen;

- kinetische uitingen.

Omdat visuele en auditive uitingen van het allergrootste belang zijn en de grootste invloed hebben op het vertaalproces, wordt er in dit artikel uitsluitend rekening gehouden met deze uitingen.

De auditieve uitingen worden verder ingedeeld in (Plewa 2015: 76):

- talige uitingen, waaronder gesproken teksten worden verstaan (d.w.z. dialogen, narratie, verbale geluiden in de achtergrond, gesprekken op de radio of televisie);

- niet-talige uitingen, d.w.z. muziek, akoestische effecten, nonverbale geluiden en geruis in de omgeving.

De visuele uitingen worden ook ingedeeld in (Plewa 2015: 77):

- talige uitingen, waarmee geschreven teksten worden bedoeld (d.w.z. voortiteling ${ }^{7}$, de titel van de film, fragmenten van krantenartikelen, fragmenten van brieven, namen van gebouwen en straten, documenten, enz.);

- niet-talige uitingen, d.w.z. compositie van beelden en scènes.

Het audiovisueel vertalen wordt als een bijzonder soort van vertalen beschouwd, waarbij de brontekst (i.e. de dialooglijsten) verband houdt met andere niet-talige com-

6 Deze bewering geldt ook voor tv-series. Tomaszkiewicz is van mening dat precies televisie deelneemt aan het construeren van sociale communicatie en dat een film alleen een kunstwerk is (vgl. Tomaszkiewicz 2008: $55)$.

7 Daarmee worden de openingstitels (soms ook - vooral in Vlaanderen - generiek genoemd) bedoeld die in het begin van een film of televisieprogramma verschijnen. Hier worden de titel van de productie, de namen van acteurs en crewleden vermeld. 
municatiemiddelen, zoals het geluid (zgn. auditieve uitingen) of het beeld (zgn. visuele uitingen). Samen met deze communicatiemiddelen vormt de brontekst de inhoud. Gambier (2009: 17) beschouwt het als een multisemiotisch mengsel van verschillende codes. Behalve het beeld en het geluid begrijpt hij onder deze codes ook kleuren, proxemiek ${ }^{8}$ en verhaal. In het geval van het vertalen van een film of een televisieprogramma wordt van de klassieke bewering uitgegaan dat het vertalen gelijkwaardig is met het overbrengen van de brontekst of het bronbericht naar de doeltekst of het doelbericht (Tomaszkiewicz 2008: 98). Tomaszkiewicz stelt in plaats daarvan voor het audiovisuele vertalen als een transfer tussen twee semiologische complexen te beschrijven (Tomaszkiewicz 2008: 100):

semiologisch broncomplex semiologisch doelcomplex ${ }^{9}$

Bij de ondertiteling laten technische en esthetische redenen niet toe de helft van het scherm met ondertitels te bedekken, opdat de hele dialogen weergegeven zouden kunnen worden. Hierdoor zal de receptie van het beeld verstoord worden. Daarnaast leest een gemiddelde toeschouwer langzamer dan hij dezelfde tekst met zijn gehoor waarneemt. Om deze reden moeten de dialogen in het vertaalproces verkort worden. De vertaler moet daarom beslissen welke informatie uit de dialogen noodzakelijk is opdat de toeschouwer de handeling van de film kan begrijpen en volgen, en welke informatie een secundair karakter heeft. Aldus worden sommige fragmenten weggelaten of omgevormd naar een beknoptere versie (Tomaszkiewicz 2008: 112v.). Bijgevolg zijn weglating en verdichting de meest gebruikte vertaaltechnieken. Als de meest belangrijke factoren die de invloed op het vertaalprocess hebben, kunnen de volgende genoemd worden (Pisarska/Tomaszkiewicz 1998: 215):

- het soort product dat vertaald wordt (televisieprogramma, film, reclame);

- het doel dat met behulp van het product gerealiseerd wordt (informeren, amuseren, ontroeren enz.);

- de relatie tussen het linguale en visuele vlak.

Tomaszkiewicz stelt vijf aspecten voor waarin deze relatie zich uit (Pisarska/Tomaszkiewicz 1998: 215v.):

1) parallelle betekenis - het talige en visuele vlak zijn bronnen van informatie, maar elk apart, d.w.z. dat zij onafhankelijk van elkaar functioneren;

2) complementariteit - het talige en visuele vlak vullen elkaar aan en de betekenis vloeit voort uit de relatie tussen deze vlakken;

3) interpretatieve relatie - het taligee vlak levert onontbeerlijke informatie om het beeld te kunnen begrijpen, en het beeld illustreert wat er gezegd wordt;

4) equivalentie - het beeld en het visuele vlak zijn bron van dezelfde informatie;

5) tegenspraak - het talige vlak levert informatie die in tegenspraak staat tot wat het beeld toont.

De relatie tussen het talige en visuele vlak speelt een enorme rol in het vertaalproces. Op basis daarvan besluit de vertaler welke elementen van het talige vlak onontbeerlijk

8 Daaronder wordt de afstand tussen personen en de daaruit voortvloeiende houding tegenover elkaar begrepen (vgl. Ottenheimer 2013: 135-139).

9 In haar eerdere publicatie noemt Tomaszkiewicz deze complexen semiologisch complex A en semiologisch complex B (Pisarska/Tomaszkiewicz 1998: 214), maar de boven vermelde benamingen schijnen duidelijker te zijn. 
zijn in de doeltekst, welke van het visuele vlak gecompenseerd worden en welke toegevoegd moeten worden opdat de toeschouwer het beeld juist kan begrijpen (Pisarska/ Tomaszkiewicz 1998: 216).

\section{Vaktaal in niet-vakkundige teksten}

De vaktaal wordt gezien als een middel dat een optimale communicatie onder vaklui over een bepaald vakgebied mogelijk maakt (Schmidt 1969: 11; vgl. Fluck 1976: 13). Hoffmann definieert de vaktaal als:

(...) die Gesamtheit aller sprachlichen Mittel, die in einem fachlich begrenzbaren Kommunikationsbereich verwendet werden, um die Verständigung zwischen den in diesem Bereich tätigen Menschen zu gewährleisten (Hoffmann 1976: 170).

Vaktermen die de exacte benaming van voorwerpen, methodes en processen mogelijk maken (Schmidt/Scherzberg 1968: 67) en een essentieel deel uitmaken van een vaktaal, kunnen echter ook in niet-vakkundige teksten voorkomen, zoals bijvoorbeeld in de literatuur. Deze termen hebben dan een andere functie. Ze fungeren niet meer als middel van de communicatie tussen vaklui, maar als medium voor wetenschappelijk geinteresseerde schrijvers (Kalverkämper 1998: 721). De ontvanger van de niet-vakkundige tekst waar vakwoordenschat in voorkomt, is een lezer die geen deskundige is; daarom bezit hij meestal geen vakkundige voorkennis.

De vaktaal fungeert in niet-vakkundige teksten als stijlmiddel waardoor er een werksfeer wordt gecreëerd (Pieczyńska-Sulik 2010: 166). Dankzij het vakjargon wordt een realistisch, of de werkelijkheid benaderend, milieu voorgesteld, wat de authenticiteit en overtuigingskracht van de roman ondersteunt. Door het gebruik van vaktermen wordt de beschrijving duidelijker en levendiger gemaakt (vgl. Pieczyńska-Sulik 2010: 167; Liimatainen 2013: 57). Naast enkele vakwoorden kunnen ook langere passages voorkomen waarin vaktermen gebruikt worden, met uitleg van vakkundige fenomenen en activiteiten (Kalverkämper 1998: 723; Liimatainen 2013: 59). Vaktaal komt niet uitsluitend in literatuur voor, maar ook in films en tv-series waarin het arbeidsmilieu van een bepaalde beroepsgroep wordt voorgesteld. Als voorbeelden kunnen hier juridische tv-series, zoals Law $\mathcal{E}$ Order en How to Get Away with Murder of medische tv-series als Private Practice, Grey's Anatomy en Call the Midwife genoemd worden, die een grote populariteit bij de toeschouwers genieten. De vaktermen worden hier ook gebruikt om een werksfeer te scheppen en haar authenticiteit te versterken. In tegenstelling tot romans worden ze ook nog door het beeld ondersteund.

Vaktermen die in niet-vakkundige teksten ${ }^{10}$ voorkomen, vormen een uitdaging voor de vertaler. Het vertalen van vakwoorden zowel in de literatuur, als ook in audiovisuele

10 Tot de niet-vakkundige teksten worden ook dialooglijsten van films en tv-series gerekend. 
teksten $^{11}$ stelt niet alleen het algemene taalvermogen van de vertaler op proef, maar ook zijn vakkennis en -competentie (Liimatainen 2013: 62). Literaire en audiovisuele teksten waarin vakwoordenschat te vinden is, worden vooral voor het amusement gelezen. Omdat de lezers of toeschouwers eigenlijk niet over vakkennis beschikken, zijn onjuist gebruikte vakwoorden in een fictionele tekst niet zo opvallend als in een vaktekst. Liimatainen (2013: 68) onderstreept wel dat van de doeltekst vakkundige correctheid verwacht mag worden, indien de auteur van de brontekst zich op vakkundige correctheid richt.

Bij het vertalen van vaktermen in audiovisuele teksten moet een andere aanpak gebruikt worden dan bij vertaling van literaire teksten, omdat er andere factoren invloed hebben op het beslissingsproces van de vertaler. Om het vertaalprobleem op te lossen staan er ook andere mogelijkheden ter beschikking. ${ }^{12}$

\section{De strijd van de vertaler tussen beperkingen en prioriteiten}

In elk soort vertalen moet de vertaler tussen twee factoren manoeuvreren die het vertaalproces beïnvloeden, namelijk beperkingen (restrictions) en prioriteiten (priorities) (vgl. Zabalbeascoa 1999). Het begrip beperking "refers to the constraining nature of the translator's circumstances, or conditions" (Zabalbeascoa 1999: 160). In het geval van ondertiteling kunnen vooral een beperkt aantal karakters en de relatie tussen het talige en visuele vlak als beperkingen genoemd worden. De term prioriteit daarentegen kan vanuit twee oogpunten gedefinieerd worden. Ten eerste, uit het perspectief van de producent van een tekst, kunnen prioriteiten als "the formal and functional characteristics that the text will have once it is finished" gezien worden; ten tweede, vanuit de invalshoek van de gebruiker van een tekst, als "characteristics that a text is interpreted as having - its explicit and implicit aspects” (Zabalbeascoa 1999: 161).

De relatie tussen beperkingen en prioriteiten heeft een complex karakter:

Rs [restrictions] are the circumstances that prevent an absolute, universal, constant type of relationship between the ST [source text] and its TT [target text] (a one-to-one relationship) from being anything but wishful (or prescriptive) thinking. The nature of the RS actually present has a limiting effect on the number and the nature of the Ps [priorities]; in turn the Ps determine the relevance of the Rs, thus creating a tension between the two (Zabalbeascoa 1999: 165).

11 Een audiovisuele tekst is een tekst die bepaalde inhouden overbrengt door auditieve en visuele middelen. Een dergelijke tekst verbindt talige elementen met andere semiotische elementen, die samen de betekenis van de tekst vormen (vgl. Plewa 2011: 211; Tomaszkiewicz 2010: 39).

12 De belangrijkste factor die er invloed op heeft is ongetwijfeld het beeld, d.w.z. het visuele vlak. Omdat het talige vlak (de dialogen) en het visuele vlak met elkaar in een relatie staan waardoor ze een parallele betekenis vormen, kan de vertaler bepaalde termen weglaten zonder informatieverlies, indien het genoemde object getoond wordt. Deze vertaaltechniek blijkt in sommige gevallen onontbeerlijk te zijn, zeker als men bedenkt dat er een beperkt aantal karakters in de ondertiteling ter beschikking staat. In het literair vertalen ontbreekt daarentegen het visuele vlak en daarom zou de weglating tot informatieverlies leiden. Bovendien kunnen literair vertalers gebruik maken van explicatie in vorm van voet- of eindnoten die in het audiovisueel vertalen vanwege technische redenen geen plaats vinden. 
Op basis van prioriteiten, gelet op beperkingen, vindt de vertaler oplossingen voor zijn vertaalproblemen. Hierbij kan de vertaler beslissen welke kenmerken voorrang hebben boven de andere (Zabalbeascoa 1999: 162). Van de ondertitelaars wordt verwacht dat ze een oplossing vinden opdat het gesproken woord (d.w.z. de dialogen), het originele beeld (de scènes) en de toegevoegde ondertiteling een juiste samenhang vormen. Bovendien moet de vertaler in aanmerking nemen dat de toeschouwers de ondertiteling in een bepaald tempo moeten lezen en tegelijkertijd het beeld te zien krijgen (Díaz Cintas 2010: 344). Gelet op het feit dat de doorsnee toeschouwer geen deskundige is, zou de vertaler bij het vertalen van vaktermen in ondertiteling een tekst moeten scheppen die begrijpelijk is voor de toeschouwer. Dit zou als de prioriteit voor de vertaler beschouwd kunnen worden. Hierbij moet weliswaar de tekst niet aan zijn vakkundigheid verliezen opdat de toeschouwer nog steeds de indruk krijgt dat de tv-serie de werksfeer van artsen, juristen enz. weerspiegelt.

\section{Analyse}

In de analyse worden medische vaktermen in de audiovisuele vertaling besproken aan de hand van het eerste seizoen van de Britse tv-serie Call the midwife. In deze serie wordt het leven van vroedvrouwen in de armenwijk East End in Londen getoond. Omdat er in de serie vooral verloskundige gevallen behandeld worden, heeft de toeschouwer met veel geneeskundige vaktermen van de verloskunde te maken. Onder deze termen zijn benamingen voor organen, chemische verbindingen en geneesmiddelen, termen betreffende zwangerschap en bevalling, benamingen voor ziektes en hun symptomen, als ook medische gereedschappen en toestellen te vinden. In dit artikel worden enkele voorbeelden van deze termen voorgesteld, waarbij een poging wordt gedaan om de invloed van het beeld op de gebruikte vertaaltechnieken te tonen en te bepalen wat de prioriteiten in het vertaalproces waren. De analyse maakt geen aanspraak op volledigheid. Er wordt slechts een gedeelte van een onderzoek gepresenteerd dat in een bredere aanpak werd uitgevoerd.

Onderwerp van de analyse is de interlinguale ondertiteling van de eerder vermelde tv-serie in het Nederlands en Pools. Het doel van de analyse is om aan te tonen met welke vertaaltechnieken de medische vaktermen in de audiovisuele vertaling van de serie vertaald werden en welke factoren invloed hadden op het beslissingsproces tijdens het vertalen en of er verschillen dan wel gelijkenissen vast te stellen zijn tussen de ondertitels in de bepaalde doeltalen. Op basis daarvan zou de vraag kunnen beantwoord worden of de vertaler zich al dan niet als prioriteit gesteld had om een doeltekst te scheppen die ondanks het voorkomen van vaktermen begrijpelijk is voor een niet deskundige toeschouwer. Daarbij wordt gebruik gemaakt van een typologie van vertaaltechnieken, die op vertaalmethodes (Übersetzungsverfahren) van Liimatainen (2013: 62v.) steunt:

- vakkundig equivalent - de in de brontekst voorkomende vakterm wordt door zijn vakkundig equivalent, meestal van Grieks-Latijnse afkomst, weergegeven;

- inheems equivalent - de vakterm wordt door een inheems equivalent vertaald; 
- hyperoniem/hyponiem - de vakterm wordt door een overkoepelend of ondergeschikt begrip vervangen;

- vervanging - de in de brontekst voorkomende vakterm wordt door een andere term met een andere betekenis vervangen;

- explicatie - hierbij gebruikt men een beschrijving in plaats van één enkele term;

- weglating - de vakterm wordt in de doeltekst weggelaten.

\subsection{Namen van gereedschappen}

In de onderstaande tabel wordt een gesprek getoond tussen een nieuw aangestelde en een ervaren vroedvrouw bij het overhandigen van gereedschappen die bij een bevalling nodig zijn.

\begin{tabular}{|c|c|c|}
\hline \multicolumn{3}{|c|}{ 1x01 „Concussed, Nonplussed” } \\
\hline $\begin{array}{l}\text { Engels } \\
\end{array}$ & Nederlands & $\begin{array}{l}\text { Pools } \\
\end{array}$ \\
\hline $\begin{array}{l}\text { - These are the tools } \\
\text { you will carry yourself. Tin box } \\
\text { for soap and nailbrush. Canvas } \\
\text { case, containing scissors, dress- } \\
\text { ings, forceps. Do continue. } \\
\text { - Gauze, sterile. Gauze, iodo- } \\
\text { form. Pinard. Enema funnel. } \\
\text { Enema syringe. Rectal tube... } \\
\text { Glass? } \\
\text { - And second rectal tube, in case } \\
\text { the first one breaks. Also glass. }\end{array}$ & $\begin{array}{l}\text { - Dit neem je zelf mee: Blikken } \\
\text { doos voor zeep en nagelborstel, } \\
\text { schaar, verband, verlostang... Ga } \\
\text { door. } \\
\text { - Steriel gaas, idioform gaas, } \\
\text { Pinard stethoscoop, lavement- } \\
\text { vloeistof, klisteerspuit, rectale } \\
\text { buis. Van glas? } \\
\text { - En nog een voor als de eerste } \\
\text { breekt. Ook van glas. }\end{array}$ & $\begin{array}{l}\text { - Te narzędzia będziesz nosiła } \\
\text { sama. Puszka na mydło. Płócien- } \\
\text { na torba z nożyczkami, opatrun- } \\
\text { kami, kleszczami. Kontynuuj. } \\
\text { - Gaza sterylna, gaza jodofor- } \\
\text { mowa, } \\
\text { słuchawka położnicza, lejek i } \\
\text { słuchawka do lewatywy, rurka } \\
\text { odbytnicza. Szklana? } \\
\text { - I druga, gdyby pierwsza pękła. }\end{array}$ \\
\hline
\end{tabular}

Tabel 1. Namen van gereedschappen in vertaling.

In deze situatie worden benamingen van gereedschappen genoemd die als vaktermen beschouwd kunnen worden, zoals forceps, iodoform gauze en rectal tube. Deze termen werden respectievelijk met hun vakkundige equivalenten naar het Nederlands vertaald: verlostang, idioform gaas, rectale buis. In het geval van idioform gaas zit er een fout in de vertaling. Dit soort gaas heet in het Nederlands eigenlijk jodoform gaas. In de Poolse vertaling zijn er zowel vakkundige equivalenten zoals gaza jodoformowa, maar ook inheemse equivalenten zoals rurka odbytnicza (i.p.v. rektalna) te vinden. In de brontext komt ook het eponiem pinard voor dat vaak in afgekorte vorm in de medische omgangstaal wordt gebruikt. Het gaat om een Pinard stethoscoop (Engels: Pinard horn) die voor het beluisteren van foetale harttonen wordt gebruikt. In dit geval is in de Nederlandse versie de volledige naam Pinard stethoscoop gebruikt, in de Poolse versie is een Pools equivalent stuchawka potozinicza te vinden. In het Pools worden ook synonieme begrippen gebruikt, zoals stetoskop potożniczy of eponiemen als stetoskop Pinarda en gewoon pinard. Het gebruik van de term stuchawka potoznicza in plaats van stetoskop Pinarda of pinard is begrijpelijker voor de toeschouwer, die meestal een leek is, dan het eponiem dat waarschijnlijk onbekend is voor een niet deskundige. Bovendien mag niet buiten beschouwing gelaten worden dat het beeld hier een belangrijke rol speelt. De toeschouwer kan namelijk zien 
dat het hoofdpersonage de gereedschappen één voor één in haar tas legt en ze benoemt. Op basis daarvan is de toeschouwer in staat het genoemde gereedschap te zien. Hij kan zich de functie ervan voorstellen, niet alleen dankzij de naam, maar ook dankzij de vorm ervan. Dit geldt ook voor de Pinard stethoscoop. Terwijl het hoofdpersonage hem benoemt, wijst ze dit gereedschap aan en neemt het vast.

\subsection{Epsom salts}

Onder de term Epsom salt wordt magnesium sulfate begrepen, een chemische stof die in de geneeskunde gebruikt wordt vanwege zijn remmende werking op krampen van de baarmoeder. Deze stof werd ook als laxerend geneesmiddel gebruikt. De naam Epsom salts wijst op de plaats in Engeland waar de stof oorspronkelijk werd gewonnen. Daarvan komt de Nederlandse naam Engels zout of Epsomzout en de Poolse benaming sól angielska of sól Epsom. Gebruikelijkere namen in deze talen zijn bitterzout in het Nederlands en sól gorzka in het Pools.

In de onderstaande tabel wordt een fragment getoond van een gesprek tussen een vroedvrouw een haar patiënte die onlangs een miskraam heeft gehad:

\begin{tabular}{|l|l|l|}
\hline \multicolumn{1}{|c|}{$1 \times 01$ „Concussed, Nonplussed“ } \\
\hline \multicolumn{1}{|c|}{ Engels } & \multicolumn{1}{|c|}{ Nederlands } & \multicolumn{1}{c|}{ Pools } \\
\hline $\begin{array}{l}\text { - I'd like my milk dried up. } \\
\text { - I know. I brought } \\
\text { you some Epsom salts. }\end{array}$ & $\begin{array}{l}\text { - Ik wou dat m'n melk opdroogde. } \\
\text { - Ik heb magnesiumsulfaat bij me. }\end{array}$ & $\begin{array}{l}\text { - Chciałbym się pozbyć mleka. } \\
\text { - Przyniosłam ci sól z Epsom. }\end{array}$ \\
\hline
\end{tabular}

Tabel 2. De term Epsom salts in vertaling.

De gebruikelijke naam Epsom salt die in de brontekst is te vinden, werd in de Nederlandse versie door het vakkundige equivalent magnesiumsulfaat vervangen dat niet aan de verdichtingsregel voldoet en voor een leek onbegrijpelijk lijkt te zijn. De term bitterzout zegt misschien ook niet veel, maar is korter. De Poolse versie vertoont eenzelfde tendens: de term sól z Epsom werd gebruikt. Vanwege de vreemde naam Epsom is deze term misschien niet begrijpelijk voor een leek.

\subsection{Ziektes en ziekelijke toestanden}

In de volgende tabel wordt de term, asphyxiation ${ }^{13}$ gebruikt in een gesprek onder vaklui getoond. De term duidt een toestand aan waarin de ademhaling belet wordt (Collin

13 Het mag niet buiten beschouwing gelaten worden dat in het Nederlands als ook in het Pools er een vakkundige en een algemeentalige benaming voor een lichaamsdeel of een ziekte bestaat, terwijl in het Engels een vakkundige benaming zowel in vakkundige communicatie als ook in de omgangstaal voorkomt (Keller 2011: 233). 
2007: 29). Deze verstikkingstoestand hangt samen met de hypoxemie en kan tot hartstilstand leiden (Kaeppel/Weiß 1998: 132).

\begin{tabular}{|l|l|l|}
\hline \multicolumn{1}{|c|}{ Engels } & \multicolumn{1}{|c|}{ Nederlands } & \multicolumn{1}{c|}{ Pools } \\
\hline $\begin{array}{l}\text { - It increases the risk of asphyxi- } \\
\text { ation. It is a showman's trick, in } \\
\text { my view. }\end{array}$ & $\begin{array}{l}\text { - De baby kan wel stikken door } \\
\text { zo'n kermisattractie. }\end{array}$ & $\begin{array}{l}\text { - To zwiększa [...] ryzyko udusze- } \\
\text { nia. Sztuczka na pokaz. }\end{array}$ \\
\hline \multicolumn{2}{|c|}{$1 \times 03$ „Maybe a Baby" } \\
\hline $\begin{array}{l}\text { - Get a towel ready. It's an as- } \\
\text { phyxiation. }\end{array}$ & - Handdoek. Het is asfyxiatie. & $\begin{array}{l}\text { - Przygotuj ręcznik. Jest przy- } \\
\text { duszone. }\end{array}$ \\
\hline
\end{tabular}

Tabel 3. De vertaling van de term asphyxiation.

Deze term werd in de tweede aflevering in elke geanalyseerde taalversie door een inheems equivalent vervangen: in het Nederlands stikken, in het Pools uduszenie. Het niveau van de vakkundigheid in de Engelse zin 'It increases the risk of asphyxiation' werd door het algemeentalige equivalent verlaagd zodat die ook voor een leek (de gemiddelde toeschouwer) begrijpelijk is. In de derde aflevering wordt daarentegen de term asphyxiation, die in een gesprek onder vroedvrouwen tijdens de bevalling voorkomt, in de Nederlandse versie door het vakkundige equivalent asfyxiatie vertaald. In de Poolse versie werd het niveau van vakkundigheid weer verlaagd door het gebruik van het algemeentalige participium przyduszony, hoewel er in het Pools een vakterm voor deze toestand _ asfiksja - bestaat.

De laatste hier geanalyseerde term is eclampsia: het is een toestand waarin de zwangere vrouw een hoge bloeddruk heeft en waarin krampaanvallen elkaar bliksemsnel opvolgen (Collin 2007: 121; Kaeppel/Weiß 1998: 240). De onderstaande tabel laat zien hoe deze term in een gesprek tussen een arts en een vroedvrouw in het Nederlands en het Pools werd vertaald.

\begin{tabular}{|l|l|l|}
\hline \multicolumn{3}{|c|}{1 1x04 „Baby Snatcher“ } \\
\hline \multicolumn{1}{|c|}{ Engels } & \multicolumn{1}{|c|}{ Nederlands } & \multicolumn{1}{c|}{ Pools } \\
\hline $\begin{array}{l}\text { - Nurse, it was eclampsia. Baby } \\
\text { didn't make it. }\end{array}$ & $\begin{array}{l}\text { - Zuster, het was eclampsie. } \\
\text { De baby heeft, t niet gehaald. }\end{array}$ & $\begin{array}{l}\text { - To była rzucawka, dziecko nie } \\
\text { przeżyło. }\end{array}$ \\
\hline
\end{tabular}

Tabel 4. De vertaling van de term exlampsia.

In de Nederlandse versie werd deze term door het vakkundige equivalent eclampsie vertaald, in de Poolse versie daarentegen door de eigen benaming rzucawka, hoewel er in het Pools de term eklampsja bestaat. Het begrip rzucawka lijkt in tegenstelling tot eklampsja begrijpelijker te zijn voor een leek, omdat het associaties met het werkwoord rzucać sie [zich heen en weer gooien] oproept, wat op de krampen wijst die tijdens deze toestand optreden (Zieliński 2004: 203).

In de volgende tabel worden twee gesprekken gepresenteerd respectievelijk tussen een vroedvrouw en de man van een patiënte: 


\begin{tabular}{|c|c|c|}
\hline \multicolumn{3}{|c|}{ 1x01 „Concussed, Nonplussed" } \\
\hline Engels & Nederlands & Pools \\
\hline $\begin{array}{l}\text { - Conchita's ankles are swollen. } \\
\text { When that happens we have to } \\
\text { check for a condition called pre- } \\
\text { eclampsia, by looking for signs } \\
\text { of protein in the urine. } \\
\text { - Pre-eclampsia? Is that the } \\
\text { same as toxaemia? } \\
\text { - Yes. It is. } \\
\text { [...] } \\
\text { - Sister Bernadette always says } \\
\text { you can't get toxaemia. except } \\
\text { with your first and second. }\end{array}$ & $\begin{array}{l}\text { - Conchita's enkels zijn opge- } \\
\text { zwollen. Dat kan op pre-eclamp- } \\
\text { sie duiden. } \\
\text { - Is dat hetzelfde als toxemie? } \\
\text { - Inderdaad, ja. } \\
\text { [...] } \\
\text { - Volgens zuster Bernadette kun } \\
\text { je dat krijgen bij je 1e of } 2 \mathrm{e} .\end{array}$ & $\begin{array}{l}\text { - Conchita ma spuchnięte kostki. } \\
\text { Sprawdzam, czy nie ma stanu } \\
\text { przedrzucawkowego, szukając } \\
\text { białka w moczu. } \\
\text { - To takie zatrucie? } \\
\text { - Tak. } \\
\text { [...] } \\
\text { - Siostra Bernadette mówiła, że } \\
\text { to się ma tylko przy pierwszym } \\
\text { albo drugim. }\end{array}$ \\
\hline \multicolumn{3}{|c|}{ 1x04 „Baby Snatcher" } \\
\hline $\begin{array}{l}\text { - The doctor did explain the situ- } \\
\text { ation? Your wife's condition? } \\
\text { - He said it's... toxaemia. } \\
\text { - It can also be called eclampsia. }\end{array}$ & $\begin{array}{l}\text { - Heeft de dokter de situatie } \\
\text { uitgelegd? De toestand van uw } \\
\text { vrouw? } \\
\text { - Hij zei dat het toxemie is. } \\
\text {-Het wordt ook wel eclampsie } \\
\text { genoemd. } \\
\end{array}$ & $\begin{array}{l}\text { - Lekarz wyjaśnił panu sytuację? } \\
\text { Stan pana żony? } \\
\text { - Mówił, że to toksemia. } \\
\text { - Taki stan nazywamy rzucawką. }\end{array}$ \\
\hline $\begin{array}{l}\text { - Help had come too late for } \\
\text { Margaret, so her eclampsia was a } \\
\text { death sentence. }\end{array}$ & $\begin{array}{l}\text { - Voor Margaret was hulp te laat } \\
\text { gekomen dus haar eclampsie } \\
\text { was een doodvonnis. }\end{array}$ & $\begin{array}{l}\text { - W przypadku Margaret pomoc } \\
\text { przyszła za późno. Rzucawka była } \\
\text { dla niej wyrokiem śmierci. }\end{array}$ \\
\hline
\end{tabular}

Tabel 5. De termen pre-eclampsia, eclampsia en toxaemia in vertaling.

In de Nederlandse versie werden de begrippen pre-eclampsia, eclampsia en toxaemia met behulp van hun vakkundige equivalenten weergegeven. Een mogelijk equivalent voor de term pre-eclampsia zou het begrip zwangerschapsvergiftiging zijn dat begrijpelijk is voor een leek, maar te lang is voor de ondertiteling en niet voldoet aan de verdichtingsregel. In de Poolse versie, werd de term eclampsia door het begrip rzucawka vertaald. Overeenkomstig hiermee werd het begrip pre-eclampsia als stan przedrzucawkowy weergegeven. De term toxaemia werd op twee manieren naar het Pools vertaald: in de eerste aflevering met behulp van de term zatrucie, die naar een vergiftiging verwijst, in de vierde aflevering door de vakkundige term toksemia.

\section{Besluit}

De uitgevoerde analyse laat zien dat het vertalen van medische vaktermen in het audiovisuele vertalen een uitdaging is voor de vertaler. Zoals eerder vermeld, wordt er van de vertaler verwacht dat hij behalve de vertaalcompetentie ook over medische kennis zou moeten beschikken. Uit de analyse blijkt toch dat er in sommige gevallen de kennis ontbrak. Verwisselings- en typefouten in alle versies bewijzen dit. De toeschouwer zou sommige, zoals idioform gaas i.p.v. jodoformgaas in de Nederlandse versie waarschijnlijk over het hoofd zien, maar andere, zoals stuchawka do lewatywy [lavementshoorbuis] i.p.v. strzykawka of gruszka do lewatywy [lavementsspuit, lavementpeer] in de Poolse versie kunnen hem in verwarring brengen. Enerzijds zou de vertaler een tekst moeten schep- 
pen die begrijpelijk is voor de ontvanger, anderzijds mag de tekst niet aan vakkundigheid inboeten. Uit de analyse blijkt ook dat de Poolse vertaalster zich als prioriteit gesteld had de doeltekst begrijpelijk voor de toeschouwer te maken door het gebruik van inheemse woorden i.p.v. vaktermen. In de Nederlandse versie overwegen daarentegen vaktermen.

In tegenstelling tot literaire teksten konden de vertalers weliswaar om technische redenen geen gebruik maken van explicatie, het zij in vorm van een intratekstuele uitleg of door middel van een voet- of eindnoot, d.w.z. een paratekstuele verklaring. De brontekst moest dus vanwege een beperkt aantal karakters in de ondertiteling verkort worden. In het geanalyseerde materiaal is de weglating relatief vaak gebruikt, vooral in het geval van het bepalend deel bij namen van instrumenten, waar de toeschouwer het doel of de functie daarvan uit de context of aan de hand van zijn vorm, die op het beeld te zien is, kan concluderen. Het beeld is bijgevolg nuttig, want de toeschouwer kan de informatie die uit de ondertitels in de doeltekst weggelaten werd, aan de hand van het beeld opmaken. Daardoor konden bepaalde elementen van de brontekst zonder wezenlijk informatieverlies weggelaten worden.

\section{Bronnen}

\section{Primaire bronnen}

Call the midwife. [DVD] Draaiboek: Heidi Thomas

Call the midwife. [DVD] Vertaling naar het Nederlands: Subs Media B.V.

Z pamiętnika potożnej. Seria 1 [DVD] Vertaling naar het Pools: Karolina Jaszczuk

\section{Secundaire bronnen}

Belczyk, Arkadiusz (2007): Ttumaczenie filmów. Wilkowice: Wydawnictwo dla szkoły.

Collin, Peter Hodgson (2007): Dictionary of medical terms. London: A\&C Black.

Díaz Cintas, Jorge (2010): 'Subtitling'. In: Gambier, Yves/ Doorslaer, Luc van (red.): Handbook of Translation Studies. Vol. 1. Amsterdam/ Philadelphia: John Benjamins Publishing Company, pp. 344-349.

Díaz Cintas, Jorge/ Remael, Aline (2014): Audiovisual Translation: Subtitling. London/ New York: Routledge.

Fluck, Hans-Rüdiger (1976): Fachsprachen. Einführung und Bibliographie. München: Francke Verlag. Gambier, Yves (2009): 'Challenges in research on audiovisual translation'. In: Perekrestenko, Alexander/ Pym, Anthony (red.): Translation Research Projects 2. Tarragona: Intercultural Studies Group. Universitat Rovira i Virgili, pp. 17-25, geraadpleegd op 25 april 2015, van http://isg. urv.es/publicity/isg/publications/trp_2_2009/TRP_2_may_3.pdf

Gottlieb, Henrik (2002): 'Untertitel. Das Visualisieren filmischen Dialogs'. In: Friedrich, Hans Edwin/ Jung, Uli (red.): Schrift und Bild im Film. Schrift und Bild in Bewegung 3. Bielefeld: AisthesisVerlag, pp. 185-214. 
Hendrykowski, Marek (1994): Stownik terminów filmowych. Poznań: Ars Nova.

Hoffmann, Lothar (1976): Kommunikationsmittel Fachsprache. Eine Einführung. Berlin: Akademie Verlag.

Jüngst, Heike E. (2010): Audiovisuelles Übersetzen. Tübingen: Narr Verlag.

Kaeppel, Volker/ Weiß, Joachim (red.) (1998): Das Wörterbuch medizinischer Fachausdrücke. Mannheim [et al.]: Dudenverlag.

Kalverkämper, Hartwig (1998): 'Fachsprachliche Phänomene in der Schönen Literatur'. In: Hoffmann, Lothar/ Kalverkämper, Hartwig/ Wiegand, Herbert Ernst (red.): Fachsprachen. Ein internationales Handbuch zur Fachsprachenforschung und Terminologiewissenschaft. Berlin/New York: de Gryter, pp. 717-728.

Keller, Nicole (2011): 'Übersetzen medizinischer Fachtexte am Beispiel des Sprachenpaars Englisch-Deutsch'. In: Panace@: Revista de Medicina, Lenguaje y Traducción 12(34), pp. 234-238, geraadpleegd op 13 oktober 2016, van http://www.medtrad.org/panacea/IndiceGeneral/ n34-tradyterm-keller.pdf

Korycińska-Wegner, Małgorzata (2011): Übersetzer der bewegten Bilder. Audiovisuelle Übersetzung - ein neuer Ansatz. Frankfurt a. M.: Peter Lang.

Liimatainen, Annikki (2013): 'Zur Übersetzung von Fachausdrücken in der Belletristik'. In: Schmitt, Peter A./ Werner, Reinhold (red.): Lebende Sprachen. Zeitschrift für interlinguale und interkulturelle Kommunikation 58 (1). Berlin: de Gruyter, pp. 57-70.

Ottenheimer, Harriet Joseph (2013): The Anthropology of Language. An Introduction to Linguistic Anthropology. Wadsworth: Cengage Learning.

Pieczyńska-Sulik, Anna (2010): 'Fachlexik in der literarischen Übersetzung'. In: Bartoszewicz, Iwona/ Dalmas, Martine/ Szczęk, Joanna/ Tworek, Artur (red.): Linguistische Treffen in Wroctaw 5. Wrocław/ Dresden: Neisse Verlag, pp. 165-172.

Pisarek, Walery (2006): Stownik terminologii medialnej. Kraków: Universitas.

Pisarska, Alicja/ Tomaszkiewicz, Teresa (1998): Wspótczesne tendencje przektadoznawcze. Poznań: UAM Wydawnictwo Naukowe.

Plewa, Elżbieta (2014): 'Wybrane zagadnienia translacji lektorskiej w Polsce'. In: Łukasik, Marek/ Mikołajewska, Beata (red.):Jezzyki specjalistyczne wczoraj, dzis i jutro. Warszawa: IKL@. Wydawnictwo Naukowe Instytutu Kulturologii i Lingwistyki Antropocentrycznej. Uniwersytet Warszawski, pp. 335-348.

Plewa, Elżbieta (2015): Uktady translacji audiowizualnych. Warszawa: Wydawnictwo Naukowe Instytutu Komunikacji Specjalistycznej i Interkulturowej. Uniwersytet Warszawski.

Schmidt, Wilhelm/ Scherzberg, Johanna (1968): 'Fachsprachen und Gemeinsprache'. In: Harig, Katharina/ Ebert, Wolfgang/ Kreutzmann, Werner/ Pichler, Rudolf/ Rößler, Rudolf (red.): Sprachpflege: Zeitschrift für gutes Deutsch 17. Leipzig: VEB Bibliographisches Institut, pp. 65-84.

Schmidt, Wilhelm (1969): 'Charakter und gesellschaftliche Bedeutung der Fachsprachen'. In: Harig, Katharina/ Ebert, Wolfgang/ Kreutzmann, Werner/ Pichler, Rudolf/ Rößler, Rudolf (red.): Sprachpflege: Zeitschrift für gutes Deutsch 18. Leipzig: VEB Bibliographisches Institut, pp. 10-21.

Tomaszkiewicz, Teresa (2008): Przektad audiowizualny. Warszawa: Wydawnictwo Naukowe PWN.

Tryuk, Małgorzata (2008): 'Co to jest tłumaczenie audiowizualne?'. In: Woźniak, Monika (red.): Przektadaniec 1, pp. 26-39.

Zabalbeascoa, Patrick (1999): 'Priorities and Restrictions in Translation'. In: Vandaele, Jeroen (red.): Translation and the (Re)Location of Meaning, pp. 159-167.

Zieliński, Krzysztof (2004): Stownik pochodzenia nazw i określeń medycznych. Antyczne i nowożytne dzieje chorób w ich nazwach ukryte. Bielsko Biała: $\alpha$-media press. 
Mgr. Michał Gąska / michal.gaska@uwr.edu.pl

Uniwersytet Wrocławski, Instytut Filologii Germańskiej, Zakład Translatoryki i Glottotydaktyki, Pl. Biskupa Nankiera 15b, 50-140 Wrocław, PL

This work can be used in accordance with the Creative Commons BY-SA 4.0 International license terms and conditions (https://creativecommons.org/licenses/by-sa/4.0/legalcode). This does not apply to works or elements (such as image or photographs) that are used in the work under a contractual license or exception or limitation to relevant rights 
